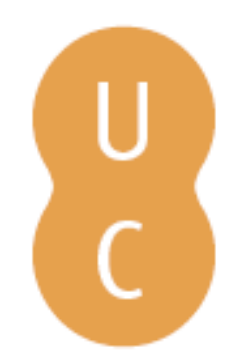

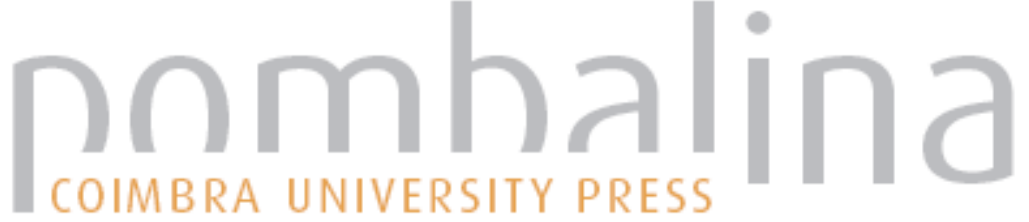

\section{À volta das três religiões do livro}

\author{
Autor(es): $\quad$ Monteiro, João Gouveia
}

Publicado por: Imprensa da Universidade de Coimbra

URL

persistente: URI:http://hdl.handle.net/10316.2/30083

DOI: $\quad$ DOI:http://dx.doi.org/10.14195/978-989-26-0310-0_2

Accessed : $\quad$ 26-Apr-2023 11:01:52

A navegação consulta e descarregamento dos títulos inseridos nas Bibliotecas Digitais UC Digitalis, UC Pombalina e UC Impactum, pressupõem a aceitação plena e sem reservas dos Termos e Condições de Uso destas Bibliotecas Digitais, disponíveis em https://digitalis.uc.pt/pt-pt/termos.

Conforme exposto nos referidos Termos e Condições de Uso, o descarregamento de títulos de acesso restrito requer uma licença válida de autorização devendo o utilizador aceder ao(s) documento(s) a partir de um endereço de IP da instituição detentora da supramencionada licença.

Ao utilizador é apenas permitido o descarregamento para uso pessoal, pelo que o emprego do(s) título(s) descarregado(s) para outro fim, designadamente comercial, carece de autorização do respetivo autor ou editor da obra.

Na medida em que todas as obras da UC Digitalis se encontram protegidas pelo Código do Direito de Autor e Direitos Conexos e demais legislação aplicável, toda a cópia, parcial ou total, deste documento, nos casos em que é legalmente admitida, deverá conter ou fazer-se acompanhar por este aviso.

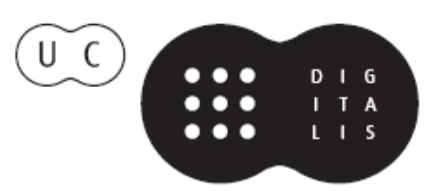




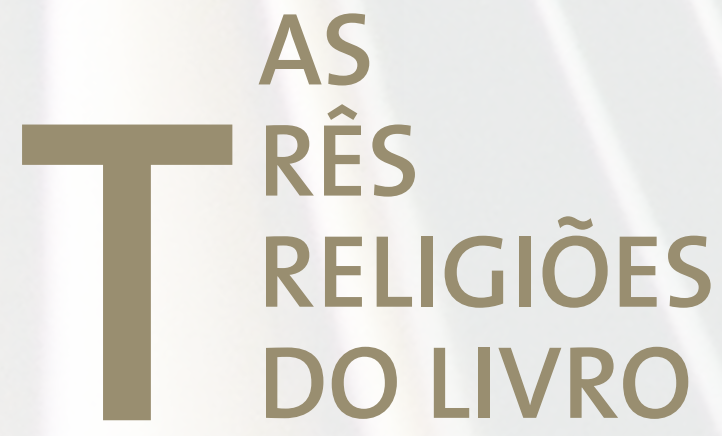

Anselmo Borges

João Gouveia Monteiro

COORDENAÇÃO 
João Gouveia Monteiro ${ }^{2}$

\section{À VOLTA DAS \\ “TRÊSRELIGIÕES DO LIVRO”}

Palavras simples as minhas, desde logo para contextualizar a realização deste colóquio, promovido pela Imprensa da Universidade de Coimbra e pela Associação Portuguesa de Editoras do Ensino Superior (uma rede que aglutina já dezena e meia de editoras universitárias portuguesas e a que a IUC actualmente preside).

O nosso mundo é o mundo do livro. E da mesma maneira que (em colaboração com o Centro de Literatura Portuguesa e com a Biblioteca Geral) temos promovido a realização de tertúlias em torno da escrita e da leitura (está, p.ex., em curso a iniciativa "10 Paixões em Forma de Romance"), pensámos que seria interessante organizar um dia de reflexão inspirado por três dos livros mais relevantes (i.é, mais editados, mais traduzidos e mais lidos) que a mão humana já escreveu: a Tora, a Bíblia e o Corão. Não para os analisar de forma individualizada, mas para os pôr em perspectiva e, com isso, abrir caminho a uma discussão enriquecedora sobre a importância do diálogo inter-religioso no mundo contemporâneo.

De facto, temos para nós que, em virtude da gravidade dos conflitos civilizacionais que agitam a nossa época, o diálogo inter-religioso se tornou num processo da maior importância. Recordando as palavras de Hans Küng, teólogo notável e autor primeiro da "Declaração de uma Ética Mundial" aprovada pelo Parlamento Mundial das Religiões em Chicago, no ano de 1993, "não haverá paz entre as nações sem paz entre as religiões. Não haverá

2 Director da Imprensa da Universidade de Coimbra entre Março de 2009 e Maio de 2011. Presidente da Associação Portuguesa de Editoras do Ensino Superior no mesmo periodo. 
paz entre as religiões sem diálogo entre as religiões. Não haverá diálogo entre as religiões sem critérios éticos globais".

Ora, nada disso nascerá por geração espontânea. Implicará disponibilidade para ouvir, curiosidade para estudar e informar, lucidez para perceber que, face às enormes transformações que ocorrem diariamente no nosso Mundo, face ao desabar de tantas crenças e costumes que julgávamos inabaláveis, face à extraordinária mobilidade a que assistimos no seio da nossa "aldeia global", é imprescindível reforçar a consciência de 'quem somos' e de 'para onde vamos'. E isso implica conhecer melhor o 'outro', pois como bem explica o nosso querido amigo Padre Anselmo Borges (que connosco pensou desde o primeiro dia este colóquio), "o outro é vivido sempre como fascinante e como ameaça. Porque o outro é outro como eu, outro eu, e, simultaneamente, um eu outro, outro que não eu", tanto podendo ser idealizado como diabolizado.

Queremos, através da diversidade religiosa que aquelas três grandes obras sustentaram através dos séculos, redescobrir a unidade essencial que é própria da identidade humana em permanente construção. Tal como propõe Juan Masiá Clavel (um dos nossos ilustres convidados) queremos ajudar à partilha daquilo que é comum e daquilo que é diferente (e, por isso, enriquecedor), queremos superar pelo diálogo aberto e público aquilo que foram os erros e as contradições históricas de todos, queremos semear e ajudar a construir um horizonte comum de linguagem e de diálogo onde haja espaço, quer para a palavra, quer para o silêncio, esse silêncio contemplativo que permite que o mistério penetre, envolva e transcenda todas as religiões e nos conduza a uma espiritualidade que está para além de todas elas.

Dir-se-á que é estranho fazermos este exercício em ambiente universitário. Não estou de acordo. Os livros que inspiram o nosso colóquio são, por si sós, criações culturais da maior relevância. Como disse Robert Alter, a Bíblia é "uma espécie de micro-cosmos de toda a experiência poética e literária do Ocidente". Por isso, o seu conhecimento não é matéria que possa escapar à cultura universitária. De resto, como tenho afirmado noutras ocasiões, as universidades (a começar pela de Coimbra) só teriam a ganhar com a valorização no seu interior dos chamados Estudos Religiosos. Não se 
trata de regressar à velha faculdade de Teologia, mas sim de reconhecer que as religiões não provêm necessariamente da superstição e que os Estudos Religiosos, com estatuto de unidade de investigação digna e bem dotada, têm inteiro cabimento no curriculum universitário. Numa perspectiva interdisciplinar, não confessional, dialogante, virada para o conhecimento das grandes tradições religiosas (não só as abraâmicas, mas também as orientais, que serão igualmente consideradas neste colóquio), devidamente inseridas nos seus contextos civilizacionais.

Universidade é conhecimento, é enriquecimento, é crescimento, é articulação (connosco, com o outro e com a comunidade), tal como "religião" pôde ser entendida (desde logo por Lactâncio ou por Santo Agostinho) como "religari" (i.é., como voltar a ligar: as nossas almas entre si e com Deus). Sobre a universidade deve pairar o espírito do conhecimento, que é também o espírito da tolerância e da partilha. Como no Livro da Profecia de Isaías (Antigo Testamento), em cujo capítulo XI podemos ler (logo no início e seguindo a bela tradução seiscentista de João Annes d'Almeida, fixada modernamente por José Tolentino Mendonça):

"Porque sairá uma vara do já cortado tronco de Jessé: e um renovo crescerá de suas raízes. E repousará sobre ele o Espírito do Senhor, o Espírito de sabedoria e de inteligência, o Espírito de conselho e de fortaleza, o Espírito de conhecimento e de temor do Senhor".

E, logo, adiante:

"Porque justiça será o cinto de seus lombos, e verdade o cinto de seus rins. E morará o lobo com o cordeiro, e o leopardo com o cabrito se deitará; e o bezerro e o filho do leão, e o animal cevado andarão juntos, e um menino pequeno os guiará. A vaca e a ursa pastarão juntas, seus filhos se deitarão juntos; e o leão comerá palha como boi. E brincará o menino de mama sobre o buraco da áspide; e o já destêtado meterá a sua mão na cova do basilisco. Não se fará mal nem dano algum em nenhuma parte de todo o monte de minha santidade: porque a terra se encherá do conhecimento do Senhor, como as águas cobrem o fundo do mar". 
Como defendia Hegel, a quem a universidade continua, naturalmente, a dedicar a sua atenção (a IUC publicou, aliás, recentemente, a obra "Still Reading Hegel", coordenada por Edmundo Balsemão Pires), na maioria dos tempos e lugares a religião tem sido uma força reconciliadora na sociedade, não uma força divisora. E a representação de Deus, qualquer que seja a forma concreta que possa assumir, constitui (nas palavras de Hegel) "o fundamento geral de um povo". Por isso a religião interessa também, sobremaneira, aos historiadores. O belíssimo texto que José Mattoso nos enviou e que será lido durante a sessão de encerramento deste colóquio, é uma prova eloquente disso mesmo.

Realizamos este evento em tempo de angústias várias, mas também de esperança. No meio de um certo desmoronamento da civilização ocidental e da crise de valores que vivemos, percebe-se uma inesperada renovação dos temas espirituais e a Igreja mostra-se mais capaz de falar uma linguagem do nosso tempo. E isso constitui um grande sinal de esperança, que incentiva o desenvolvimento dos estudos de antropologia religiosa, sem medo de a História Comparada das Religiões aparecer como caminho para o indiferentismo e o relativismo religioso.

Neste colóquio, vamos começar por tentar perceber se existe uma relação directa entre o monoteísmo (que as três religiões abraâmicas professam) e o fundamentalismo religioso dos nossos tempos. Juan José Tamayo Acosta, pensador respeitado e escritor prolífero, guiar-nos-á no arranque dessa reflexão, que constituirá também o tema da mesa-redonda desta manhã. Aqui tomarão assento, sob a sábia moderação de António Barbosa de Melo, membros das três comunidades religiosas abraâmicas: Esther Mucznik, Isabel Allegro de Magalhães e Abdoolkarim Vakil. Com eles, à volta do Judaísmo, do Cristianismo e do Islão, respectivamente, estaremos também à volta dos livros e da leitura. Como no Livro da Profecia de Jeremias (Antigo Testamento), quando, (cap. XXXVI), no ano quarto de Joaquim, Rei de Judá, veio esta palavra a Jeremias do Senhor, dizendo:

"Toma-te um volume de livro, e escreve nele todas as palavras, que te falei de ti de Israel, e de Judá, e de todas as gentes, desde o dia que te falei a ti, desde os dias de Josias até aos dias de hoje. (...) Então Jeremias 
chamou a Baruch, filho de Nerias; e Baruch escreveu da boca de Jeremias todas as palavras do Senhor, que lhe falara em um volume de livro. (...) Leu depois Baruch naquele livro as palavras de Jeremias em a Casa do Senhor (...), a ouvidos de todo o povo. (...) E disse-lhes Baruch: De sua boca ditava-me [Jeremias] todas estas palavras; e eu escrevia no livro com tinta".

Mas não queremos discutir apenas as palavras destes livros, mas também as experiências, as acções, os projectos e os sonhos a que elas deram lugar. Queremos desfazer equívocos, facilitar entendimentos. Perguntaremos: será o Deus único das religiões monoteístas sinónimo de opressão, de totalitarismo, de intolerância? Serão estas três religiões (monoteístas, abraâmicas) caminhos distintos de um mesmo caminho?

Da parte da tarde, as 'religiões do livro' (religiões de profetas) entrarão em diálogo com as chamadas 'religiões místicas'. Anselmo Borges (ele próprio autor recente de um livrinho maravilhoso editado pela IUC, intitulado "Religião e Diálogo Inter-Religioso") dar-nos-á o prazer de guiar esse debate, que decerto nos levará até ao Oriente, à descoberta das tradições e da matriz cultural dos Hindus e dos Budistas, auxiliados pelas reflexões presenciais de Adriano Moreira e de Juan Masiá, mas também por um pequeno mas muito estimulante texto enviado por Carlos João Correia.

A encerrar, teremos então oportunidade de escutar a reflexão de José Mattoso (que foi à História da Idade Média peninsular buscar testemunhos muito concretos da relação entre cristãos, muçulmanos e judeus) e, claro, a presença de Jorge Sampaio, que intervirá na sua qualidade de Alto Representante da ONU para a Aliança de Civilizações. Jorge Sampaio que, como sabem, foi recentemente doutorado bonoris causa na Universidade de Coimbra, cerimónia relevante e que iremos recordar também, através da apresentação (por Rui de Figueiredo Marcos) do livro alusivo que a IUC, com o precioso apoio da Fundação Eng. ${ }^{\circ}$ António de Almeida, preparou para a ocasião.

Bem-hajam todos aqueles que nos ajudaram a montar este programa ao longo de mais de meio-ano. Os protagonistas (que vieram de Lisboa, de Madrid, de Londres, até de Tóquio) para connosco partilharem a sua imensa sabedoria sobre estes temas. Os moderadores das mesas-redondas. 
A Faculdade de Letras, que acolheu generosamente este evento. A Reitoria da Universidade e o Clube dos Empresários de Coimbra (aqui representado pelo seu ilustre Presidente, Dr. Pedro Vaz Serra), que o viabilizaram financeiramente. O Diário de Coimbra, que o ajudou a divulgar na nossa região. E, obviamente, a pequena equipa da Imprensa da Universidade de Coimbra (em especial a sua Directora-Adjunta, Dra. Maria João Padez, e a Técnica Superior, Dra. Carla Rosa), que comigo o produziram e organizaram. A todos, muito obrigado. A quem nos deu o benefício da sua confiança e aqui acorreu em grande número para assistir ao que para vós preparámos carinhosamente, estou também muito grato pelo interesse e pelo estímulo que assim nos quiseram dispensar. 